\title{
Textual Research on Henna Art Introduced into Ancient China Through the Silk Road
}

\author{
Xue Yang ${ }^{1} \&$ Yu Liu ${ }^{1}$ \\ ${ }^{1}$ Fashion \& Art Design Institute, Donghua University, Shanghai, China \\ Correspondence: Yu Liu, Fashion \& Art Design Institute, Donghua University, 1882 West Yan'an Road, \\ Changning District, Shanghai, China. Tel: 131-2037-2094. E-mail: liuyu32@dhu.edu.cn
}

Received: June 18, 2020

Accepted: August 3, $2020 \quad$ Online Published: August 31, 2020

doi:10.5539/ass.v16n9p21

URL: https://doi.org/10.5539/ass.v16n9p21

\begin{abstract}
Since ancient Egypt, henna has been widely used as dyes for women's henna body art. Through the Silk Road, China assimilated cultures of its Western Regions, India, and Persia, such as the henna art. In Ancient China the "garden balsam" is always called "henna". Nevertheless, they belong to two different kinds of flowers. Folks' mixed use of these two kinds of flower names reflects the profound impact of the henna art on Chinese traditional culture of decorative nails. This textual research results revealed that in ancient China the customs of dye red nails are affected by foreign henna art and there were three development stages: the introduction period (from the Western Jin Dynasty to the Tang Dynasty), the development period (in the Song-Yuan Dynasty) and the popularity period (in the Ming-Qing Dynasty).
\end{abstract}

Keywords: henna art, garden balsam, nail dyeing, Miniature painting, the Silk Road, cultural exchange

Henna has been widely used in nail dyeing and hands painting from ancient Egypt to the west coast of the Mediterranean and North Africa. The traditional Chinese clothing covers the majority of the body parts of women, except the face and hands. Women's hands have become the body parts more described by Chinese literature and art since ancient times. From The Book of Songs: "Hands are slender just like the flowers of the Catkin"; "Ten slender fingers like fresh and tender red tips of bamboo shoots"; "The white fingers like the roots of green onions". With the opening of the ancient Silk Road and the deepening of Asian culture exchanges, henna art was introduced into China and became fashionable. From then on, the red fingernails of Chinese women firmly attracted the eyes of the world, became the interest and charm of the boudoir and aesthetic objects, touched the beauty of the ancient Chinese female. In this paper, images and ancient Chinese literature documentation research are combined to make a further study of women's henna art along the silk road and its influence on ancient Chinese convention of dye red nails.

\section{Chinese and Foreign Henna}

After exploring previous research results, the Chinese historical documents, ancient literary works, and folk saying, we can found that in ancient China the "Garden Balsam" always called "Henna". However, they belong to two different kinds of flowers.

\subsection{Different Flowers with the Same Name}

Henna is a transliteration of the Semitic plant name. It is also known as "Hanā" in Persian, "Lawsonia inermis Lina" in Latin, "Mendhikā" or "Mendh̄̄" in Sanskrit, and "Mehndi" in Hindi. Henna is a genus of Angiosperms-Dicotyledons-Primordia-Myrtle-Lythraceae-Lawsonia Linn (Editorial Board of Flora of China, 2004, p. 111). It blooms from June to October (Figure 1). The traditional henna paste used for dye nails and hand painting is a paste made from the leaves of henna ground into powder. The earliest relevant records of this plant in China can be found in The State of Vegetation in Southern China, written by Ji Han (263A.D.-306A.D): Henna trees are five or six feet tall, with the soft barbarian and leaves like tender Elm leaves. It is as white as frangipani and jasmine, and its fragrance is almost the same. It is also the Hu people transplanted to the South China Sea from the Ancient Roman Empire and the Near East. This flower is very tiny, just like half a rice. It smells so good that people always fold it down their sleeves and put it in the middle of their sleeves for incense. It is also known as flakes flowers. Because when its petals float in the air, they look like many white tiny flakes.

Besides, many ancient Chinese documents also refer to call the garden balsam which is commonly used for 
Chinese traditional nail dyeing as henna. According to The Anthography of Blossoms, written by Wang Xiangjin (1561-1653) in the Ming Dynasty: Garden balsam or call it henna, Dry-land pearl or small peach blossom (Wang Xiangjin, Chinese Ming Dynasty edition, Volume.23). According to The Compendium of Materia Medica written by Li Shizhen (1518-1593) in the Ming Dynasty: Garden balsam is named Quick-temper, Dry-land pearl...henna (Li Shizhen, 1997, p. 1209-1210). According to The Herbal for Relief of Famines, written by Zhu Su (1361-1425): The Little Pinkish is also known as henna, the universal name Nail Grass. It's very common to find it in ordinary people's gardens, everywhere. The flowers are more than two feet tall and have leaves like those of a peach tree but narrower, and with thin serrated edges ( $\mathrm{Zhu} \mathrm{Su,} \mathrm{2008,} \mathrm{p.} \mathrm{79).} \mathrm{The} \mathrm{Agricultural}$ Administration Book published in 1639, to continue to use this appellation, to confuse garden balsam with henna.

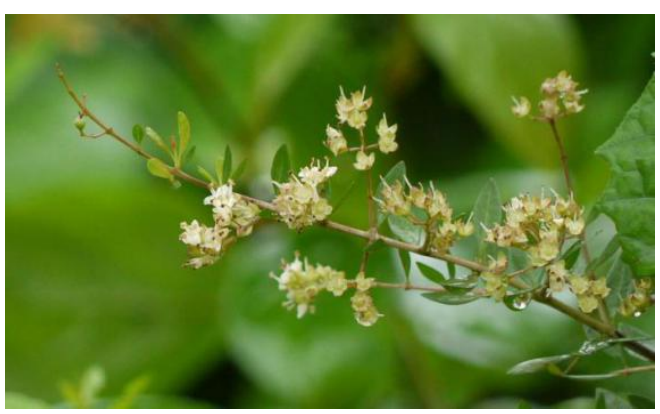

Figure 1. Flowers of henna

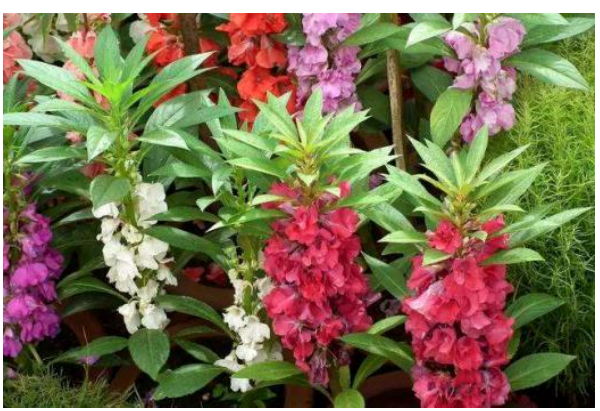

Figure 2. Flowers of garden balsam

The garden balsam (Figure 2) is a genus of Magnoliophyta-Dicotyledoneae-Rosidae-Geraniales-Balsaminaceae -Impatiens, alias nail peach, the Latin name is "Impatiens balsamina L." It stems from China. The colors of the flowers are pink, red, white, purple, yellow, and so forth. The flowering period is from June to August. Mashed petals can be used for staining nails. According to ZaoLin Miscellany written in the Qing Dynasty, by Tan Qian (1594-1658): Henna has tiny yellow flowers in May and June, similar to Osmanthus. It has a very sweet smell. Paint nails with henna redder than garden balsam (Tan Qian, 2006, p. 462), that identifies henna and garden balsam as two kinds of flowers.

\subsection{Growth and Distribution of Henna}

Henna is a shrub that must be five years old to mature and produce leaves with more pigment. Native to semi-arid regions of East Africa and South Asia. Henna grows better in arid regions than in wet ones and is habitually grown in areas with little precipitation, long droughts, and temperatures as high as 45 degrees Celsius during the day and no less than 11 degrees Celsius at night. Henna accumulates enough tannin in areas with the highest daytime temperatures. And the paste can be dyed a deep, almost black red. Henna from these regions can be dried and ground into a powder for mass sales. However, from a moist environment is suitable for fresh use as the pigment tannin content is relatively low and is not suitable for dry powder.

The local climate in China is not very suitable for henna's growth. Currently, henna is only cultivated in Guangdong, Guangxi, Yunnan, Fujian, Jiangsu, Zhejiang, and other provinces of China. Due to the restrictions of ancient climate and planting technology, henna could only be cultivated in the Lingnan area. This is the main reason why henna is not widely used in north-central China. However, the restriction of objective factors did not stop the ancient Chinese women's pursuit of beautiful nails. The Chinese have replaced henna with garden balsam, which is easier to grow and grow in their native areas and can also stain the nails red.

To sum up, from the botanical classification point of view, henna and garden balsam belongs to a completely different plant genus, and are two different plants. However, in China, it is common to confuse the two names. This phenomenon reflects the profound impact of the widespread of henna art along the ancient Silk Road on the Chinese nail decoration.

\section{Henna Art Outside of China}

Quite a few areas along the ancient Silk Road have a long tradition of henna art. The opening and development of the Silk Road provided a platform for deeper economic and cultural exchanges between the East and the West. Persia, India, and Arabia, as the key regional nodes of the Silk Road cultural interchange, have played a crucial role in promoting the introduction of henna culture into China. We can find traces of henna art in the numerous miniature paintings that exist in these places. 


\subsection{Along the Mediterranean Coast}

The Escorial illustrated in Figure 3 is based on a 13th-century manuscript of the Question of Chess from the library of The Monastery of St. Lorenze del Escorial in Spain. The manuscript was commissioned by King Alfonso X of Spain from 1251 to 1282 as a game guide. The players including Muslims, Jews, Christians, adults, children, men, women, whites, and blacks, reflecting the king's diverse court culture.

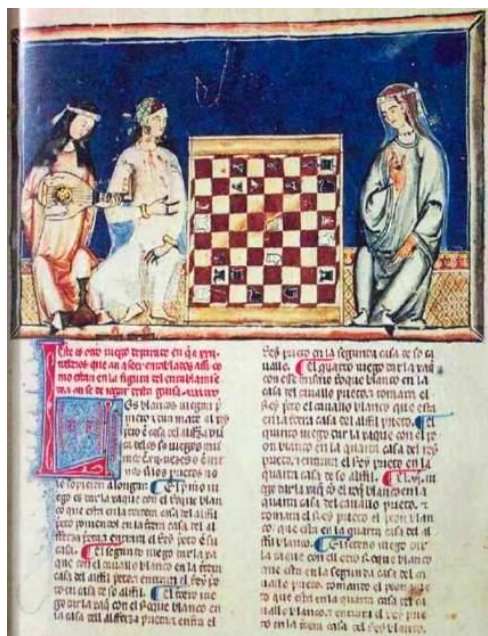

3(a)

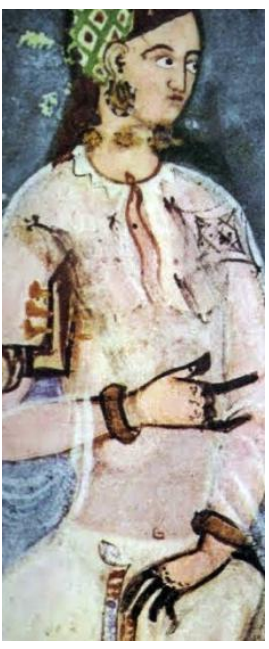

3(b)

Figure 3. Andalusian women with henna fingers

The women in the illustration are identified as Muslims through the analysis of tiaras and clothing information. The depiction of their hands shows the prevailing decoration style of henna. They from fingertips to refer to the root of henna impregnation, present as black. The palm, back of the hand, wrist, elbow, and foot are not painted except for simple pattern painting on the hand. This hand decoration makes the skin of the hands fairer by contrasting their bright color. It is not difficult for a woman to paint her dominant hand with henna, but it is fairly difficult to get both hands beautifully patterned. The figure in the women's hands have henna decoration, that means it is painted by someone else to help her do dye, or their servants, or the society has specialized in henna paint dye craftsmen.

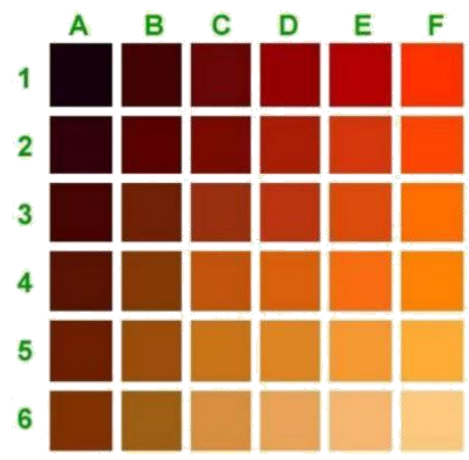

Figure 4. Dyeing renderings of henna

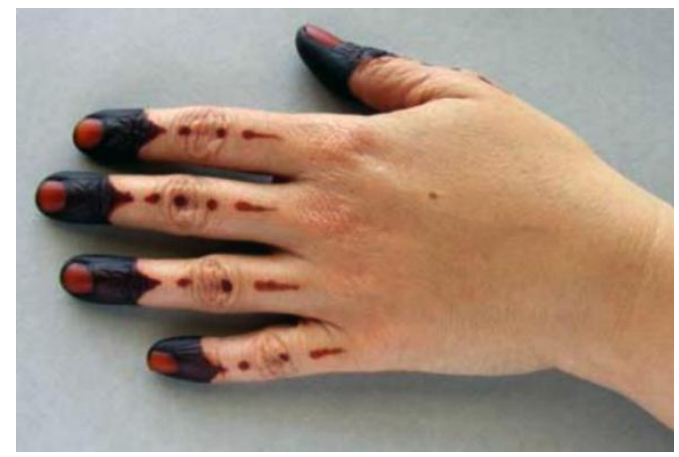

Figure 5. The fingers were stained with henna and coated overnight

The fingers we see in the illustration are almost black, however, painted with henna results in red color (Figure 4, Cartwright-Jones, C. 2009, p. 9). The quality and concentration of henna cream and the length of time it stays on the skin will directly affect the shade of the color. The higher quality and concentration of the henna cream and the longer it stays on the fingers, the more pigment will be immersed in the skin to dye them and the darker red color of fingers will be (Figure 5, Cartwright-Jones, C. 2009, p. 8). The near-black fingers of the women in the illustration show that their fingers have been dyed for a considerableperiod But, if a woman has so much more free time to wrap her fingers in henna cream for hours, and then spend another few hours painting patterns and drying them, it means she doesn't have to take part in work all day long. Thus, almost the black fingers were interpreted as a symbol of social class and identity prestige. 


\subsection{In Central and Western Asia}

Another area where the tradition of henna art was established was ancient Central Asia represented by the Arabs and Persians. The earliest records of henna in this region appear in the 10th-century Persian poetry, centuries before the Indian. The Persians to praise the beauty of the flower henna nails in various ways. Since the 12th century, fingers decorated with henna have appeared in large numbers in exquisitely painted Persian ceramics (Figure 6) and miniature manuscripts. These visual image descriptions and the location of the Persian henna decorations recorded in literature. The information such as patterns, colors, techniques is very consistent.

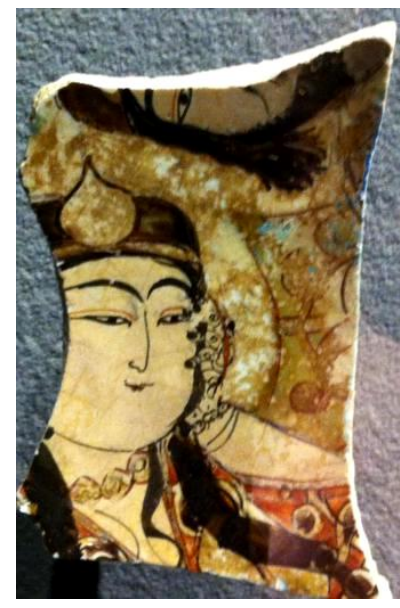

6(a)

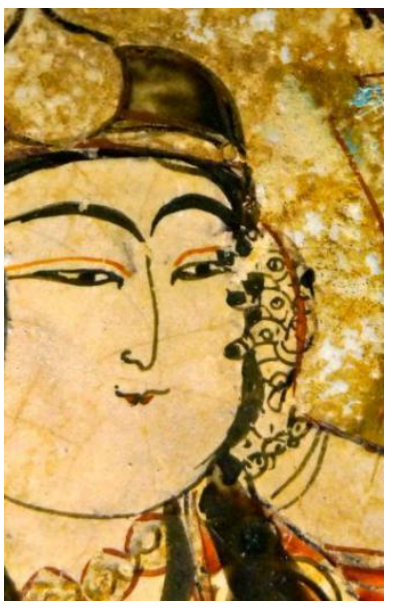

6(b)

Figure 6. Persian potsherd, from the Louvre Museum

The illustration shown in Figure 7 is called "Listening to the Scholar". It comes from a collection of Baghdad adventures and was painted in 1237 AD. The writer is Abu Muhammad al-Qasim Ibn 'Ali al-Hariri (1054-1122), a famous Arab writer and poet. The manuscript is in the Paris Library. The detailed illustrations in the codex reflect the tastes of middle-class women in the Arab world at the time and the everyday fashions of henna art.

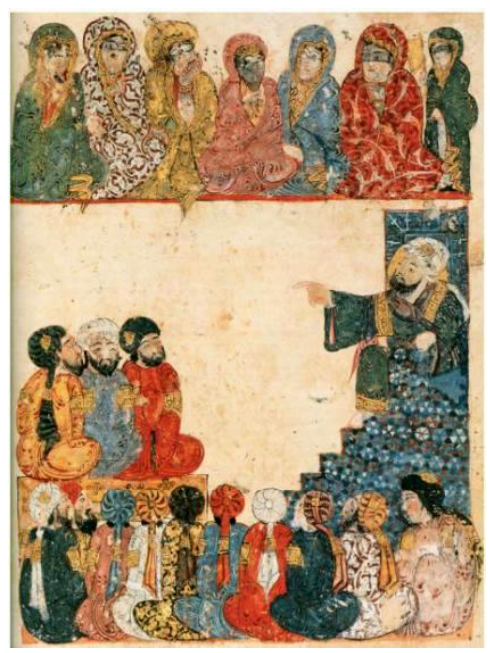

$7(\mathrm{a})$

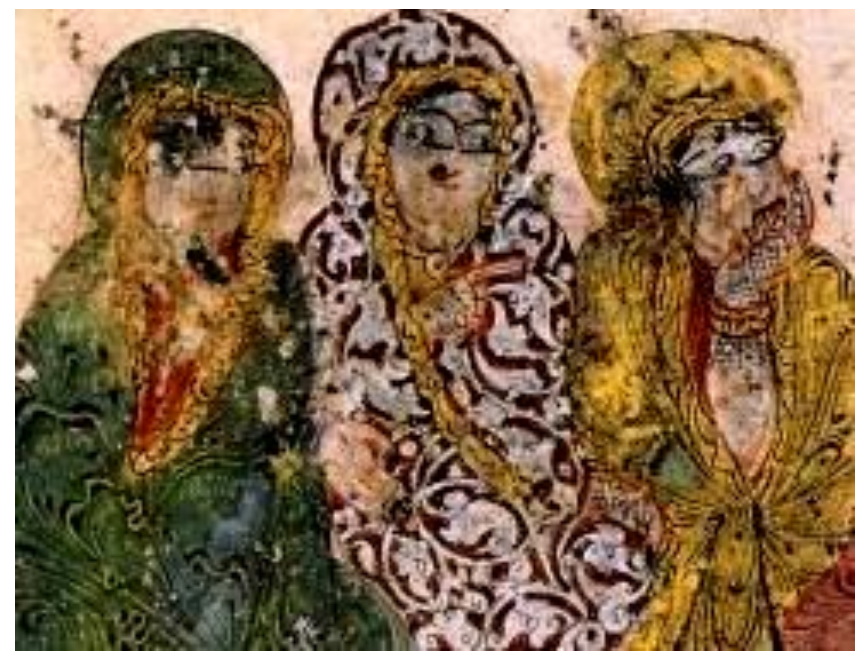

7(b)

Figure 7. "Listening to the Scholar", Persian miniature of the 13th century

We can clearly distinguish three females figures dyeing with henna from this illustration. They are the three women first, second, and third from the top left. The one on the top left, wearing a green cloak reached out to the woman beside him, as if in response to the scholar's speech. The second woman in a flowery cloak held her hand out of her skirt and pointed to the learned man. The third woman in the yellow cloak, with one hand, propped on the other arm, and her chin resting on her chin, listened with fascination. Their hands have henna decorative patterns, the position from the fingertip to the wrist. The hand pattern of the lady in a yellow cloak that reaches to the forearm is probably the most popular henna pattern in Baghdad in 1237. 

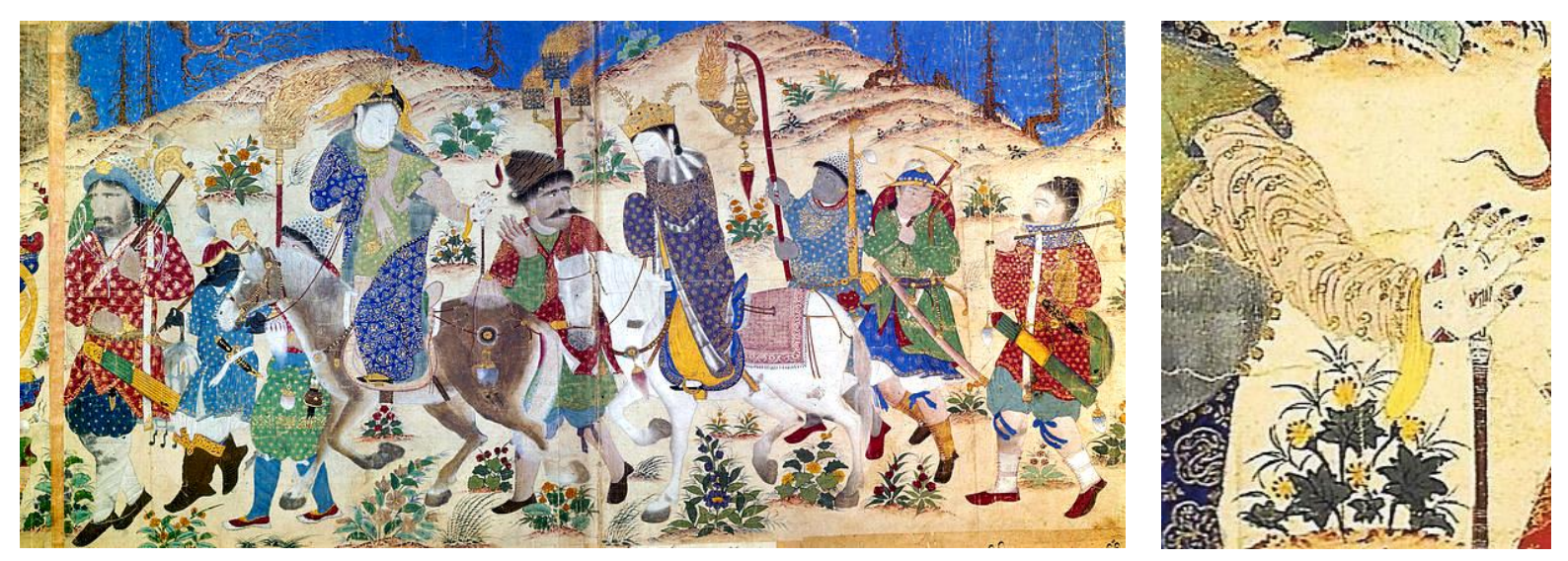

Figure 8. "Wedding Procession", Turkish miniature of the 15th century

"Wedding Procession" is one of the most famous miniature paintings in Turkey in the 15th century. It is now in the Topkapi Palace Museum in Turkey (Figure 8). This is a wedding or farewell procession through the mountains in the evening. Among them, two female figures on horseback wear traditional Central Asian clothing in Mongolian style. On the left side of the picture, the equestrian guided woman's hands are painted with henna patterns. Her fingernails and the back of her hand are decorated with deep red geometric patterns. In Persian and Arab culture, henna patterns are the symbols of good luck. The various colors of henna will be dyed on the nails when getting married, which contains the implication of growing old together and having more children. This illustration is an important proof of henna art's use in wedding celebrations.

Figure 9 is a Miniature illustration of the "Nomad Camp", which depicts the henna pattern popular in Persia in the mid-16th century. It comes from a manuscript of the "Hasam" painted between 1539 and 1543 and is now in the Harvard University Art Museum. It depicts 21 male figures of different ages and social status, without any paint on their hands or feet. There are also 11 female figures among whom henna patterns on the hands and feet of several young women can be distinguished.

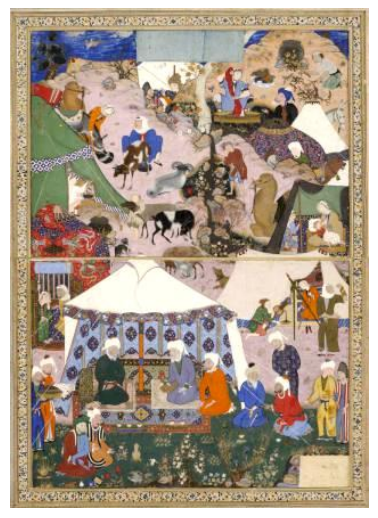

$9(\mathrm{a})$

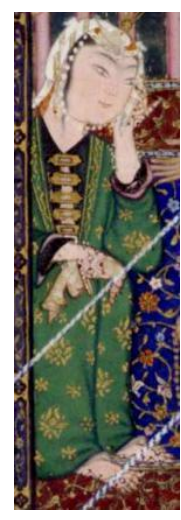

9(b)

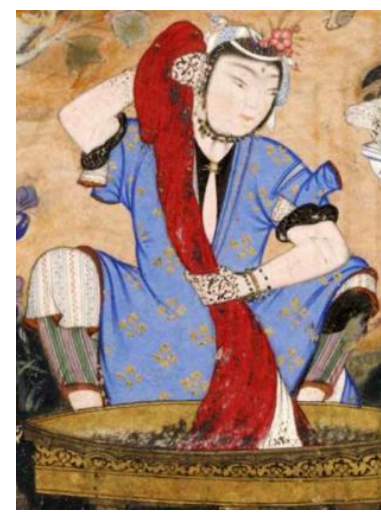

$9(\mathrm{c})$

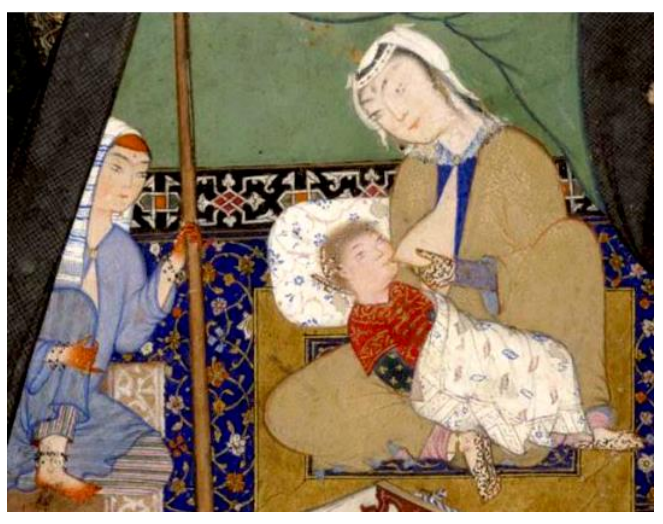

$9(\mathrm{~d})$

Figure 9. "The Nomad Camp", Persian miniature of the 16th century

Figure 9 (b) shows a woman in a green robe listening intently to the conversation of the men in the tent. Her hands and feet are painted with diamonds, triangles, and henna patterns in human form. Figure 9 (c) shows a woman in blue robe washing clothes, her fingers stretched down to her wrists in henna patterns of floral foliage. Figure 9 (d) shows the two women, on the right side are responsible for the nursing of the maid of hand and foot had complicated tangle flowers of henna patterns and design scale is very delicate. A woman is wearing a light blue robe on the left has red marks on her hands and feet, as if henna cream had been wrapped overnight. It is customary in Persia to dye and wrap the hands and feet with henna before giving birth to ward off evil spirits. If the woman is unfortunate enough to have a difficult birth, it can keep her beautiful after death. So when the henna is first opened at the end of labor, the pattern will be blurred by sweat. The pattern will become clearer as the dye deepens.

According to medieval documents, henna has been an important and widely traded commodity and medicine in the Mediterranean economy since ancient times. Henna is mentioned in a Jewish-Arabic medical dictionary from 
the 13th and 14th centuries. The text is from the Ben Ezra Synagogue storehouse, now numbered A539-4, in the John Ryland's library at the University of Manchester. The Judeo-Arabic title of the entry "henna" in the document can be read. henna's primary use seems to be as a dye for body and hair coloring. Through the existing miniature paintings, we can see that henna art is a time-honored tradition of body beautification and decoration in the Mediterranean, Persian, and Arab regions. In different historical periods, henna art formed different styles and developed intricate and detailed henna patterns, which became a symbol of women's social status.

\section{Henna Art Was Introduced Into China and Developed Locally}

With the opening of the Silk Road and the deepening of cultural exchanges between the East and West Asia, the henna art and the custom of painting red nails were gradually introduced into China. In the process of absorbing henna art, China has experienced three development stages: the introduction period (from the Western Jin Dynasty to the Tang Dynasty), the development period (in the Song-Yuan Dynasty), and the popularity period (in the Ming-Qing Dynasty).

\subsection{The Introduction Period}

At present, the earliest document to record the henna art was introduced into China is the book Southern Vegetation written in $304 \mathrm{AD}$ by Ji Han, which recorded: Henna...Hu people were transplanted from the State of ancient Roman along the Mediterranean to the South China Sea. The Records of Local Conditions and Customs in South China is another book written in $875 \mathrm{AD}$, by Duan Gonglu, which recorded: Henna, tiny and white, very fragrant. It is now cultivated in China by many foreigners...They were transplanted to China from Persia...They were originally a foreign flower and introduced to China in $536 \mathrm{AD}$. From these two documents, it can be concluded that henna was introduced and planted in ancient China no later than 536 AD during the Period of Wei, Jin, and Southern and Northern Dynasties.

The Tang Dynasty, the economic and cultural exchanges between the Chinese section of the Silk Road and the Arab-Persian region were unprecedented. The Arab and Persian merchants and the Muslim doctors came to China with a large number of foreign crops and medicinal plants. They successfully transplanted them to China. Material exchanges brought cultural exchanges, and the custom of painting red nails spread to China with Muslim women from as far away as China.

However, due to the traditional Chinese Confucian education for the body of social discipline to protect their own body, hair, skin. It is forbidden to destroy not or defiled. As a result, the Persian, Arabic, and Indian styles of henna art, which is extensively painted on hands, feet, and body, have not been popularized in China. Chinese women have only chosen to paint red nails as their body decoration.

The poem "Listen to Play GuZheng" written by Zhang Hu (785-849) says: Fingers like tender red bamboo shoots, like goose feathers flying gently on the strings. This poem depicts the delicate and moving hands of the GuZheng lady, especially her red nails, which firmly attract the poet's eyes. Zhang Hu had another poem "The Tartar Pipe", which describes a lady who played the tartar pipe: A delicate pipe played exquisite music, the rosy fingers were long and thin.. The poem "Slim Fingers" by Zhao Luanluan, a famous courtesan of the Tang Dynasty, also states: Her hands were thin as spring onions, hidden in her silk sleeves. Yesterday on the string of the lute, leaving the trail of scarlet nails.

And there are also many feminine images in Li He's poem. He is a famous poet in the Tang Dynasty. He was written a poem entitled "The Song of the Court Ladies": With the bright moon high in the sky, the Court Ladies pounded the red flower paste-up at night, indicating that in the Tang Dynasty the Court has the custom of tamping flowers dyed red. Yang Weizhen, a poet at the end of the Yuan Dynasty, wrote in his poem "Nail Flowers" say: Mashed balsamine cream at night, the fingers are all dyed like red-billed chough, which supports Li He's poem about making the balsamine dye cream that can paints nails bright red. In the Tang Dynasty, a man whose last name is Yuwen quoted a passage in the book The Makeup Stage: Woman painted her nails red. According to the book 'Textual Criticism of Things' says, 'It is said that Yang Guifei was born with red fingernails, the so-called monster of a white crane, and women in the court followed her by painting red nails as a trend. Despite Textual Criticism of Things is lost and the anecdotes of Yang Guifei are unexamined either, this quotation also proves that the custom of painting red nails has become a fad in the Tang Dynasty.

Although henna was introduced into China and transplanted successfully in the Tang Dynasty, the flour paste for nail dyeing recorded in literature was still mainly made by garden Balsam. Also, the custom of painting nails leads the way in this period by the court women, geisha girls, and prostitutes. Considering the introduction of henna, and its growth habits, it is mainly planted in the Lingnan region in China. Moreover, excessive precipitation in the southeastern region directly affected the pigment accumulation level of henna. Therefore, the 
growth quantity and pigment quality of henna in China cannot support the daily dye consumption of the vast court and the ordinary people in China. Only a few south Nanyue (A regime in the Lingnan region from the late Qin Dynasty to the Western Han Dynasty) women can dye nails with henna. Therefore, it is not difficult to understand that the garden balsam, which has strong growth adaptability, rich yield, and dyeing effect comparable to henna, is more commonly used in China.

What's more surprising is that the analysis in the field of modern biochemistry proves that the garden balsam in China and the henna from the West are very similar in their effective plant pigment and medicinal chemical composition, despite the great difference in species. According to Lin Qishou's The Chinese Herbal Composition Chemistry recorded: The effective dye of henna is Lawsone (C1OH3O6), a yellow needle crystal with a melting point of $192^{\circ} \mathrm{C}$ (decomposition), obtained from the leaves of henna. The effective dye of garden balsam is 2-methoxy-1, 4-naphthoquinone (C11H3O3). It is the methyl ether of Lawsone. It is also a yellow needle crystal with a melting point of $183.5^{\circ} \mathrm{C}$, obtained from the flowers of garden balsam (Lin Qishou, 1973, pp. 185). The ancient Chinese ancestors were able to find and successfully use garden balsam as an alternative raw material for henna, which is probably due to the wisdom and the accumulation of plant experience.

\subsection{The Development and Popularity Period}

By the Song Dynasty, dyeing red fingernails had come into view from the court, geisha girls and prostitutes to the public, and gained a wider and deeper social popularity. Parents Support Leisure Reading Notes is a book written by Zhao Yi (172-1814) who is a famous historian in the mid-Qing Dynasty recorded: The custom of dyeing red nails has been widespread since the Song Dynasty. Notes Written on Guixin Avenue written by Zhou Mi (1232-1298) who is an adherent of the Southern Song Dynasty: Take the red petals of garden balsam and mash it to make a paste. Add a little alum to it. At first, clean the nails, then apply the flower paste to the nails, wrap them in silk, and leave them overnight. The color that begins to dye is very shallow, dye continuously 3 to 5 times, the red that much dye comes out is like rouge same, wash also do not fade. It can last for months until the nail grows out and the red color fades. Many Muslim women today enjoy doing this, and some have fun teasing cats and dogs with their dyed red fingers. This document describes in detail the complicated process of dying red nails with garden balsam, which is a precious historical record of Chinese traditional nail art.

Garden balsam became a special plant associated with female images and cultural images in the literature and art history of the Yuan Dynasty due to its ability to colored women's nails. The literature describing the custom of painting red nails is more extensive than in previous eras. For example: Fashionable in society to paint fingernails in red, girls mashed impatiens in a golden basin at night ("Autumn Poem”, written by Zheng Kuiqi). Her fingers are like red maple leaves and bamboo shoots, as orangutan blood smeared on spring onions ("Fu Poem for the Woman Dyed Her Nails Red", written by Zhou Wenzhi). Her thin fingernails wiped tears, dyed red as the chalcedony and the red-crowned crane ("Red Fingernails", written by Zhang Kejiu ). A little melancholy on the parrot beak, with so much spring on the Peony sprouts ("Red Nails", written by Qu You). The description of red nail color in the poetry of this period shows multilayered color perception and gives rise to many vivid associations of color aesthetic images.

During the Ming and Qing Dynasties, the popularity of stain red nails became a folk festival activities. On Dragon Boat Festival, Double Sixth Festival, and Qixi Festival, young girls will get together. They put the garden balsam in a basin and grind the pestle to make the dyed paste to dye their fingernails red. It is a seasonal fashion, to show their beauty and meaning auspicious. According to the record in Two Collection of The West Lake written by Zhou Ji (1446-1505) in the Ming Dynasty: It is a custom in Hangzhou to pound the garden balsam with juice and dye nails red, just like ruby, is very beautiful. According to the County Annals of Jiading that is a book written in the Wanli Period of the Ming Dynasty in Shanghai contains: The girls pray for handicraft in the courtyard, pounding the flowers of garden balsam to dye her red nails. The scarlet hues are like amber. It won't fade for months. According to the record in the County Annals of Qujiang written in the Guangxu Period of the Qing Dynasty: On this Dragon Boat Festival...The woman put Mugwort in her hair, and the girls pounding the flowers of garden balsam to dye red nails.

In addition to the eastern region, the industrious and beautiful Uygur women in the western region also love this activity very much. They call it "Hainai", and they dye their finger and toenails with the juice of the newly grown sour grapes mixed with the juice of henna. The beauty of "Hainai" has been passed down for generations and made a distinctively beautiful scene.

\section{Conclusion}

Henna has been a widely used dye plant from western China to the west coast of the Mediterranean and northern Africa since ancient Egypt. With the opening of the Silk Road and the deepening of cultural exchanges between 
east and west Asia, henna art gradually spread eastward. Persia, India, and Arabia, as the key regional nodes of the Silk Road art interchange, have played an important role in promoting the introduction of henna culture into China. In ancient China, the customs of dye red nails are affected by foreign henna art and there were three development stages: the introduction period (from the Western Jin Dynasty to the Tang Dynasty), the development period (in the Song and Yuan Dynasties), and the popularity period (in the Ming and Qing Dynasties). The "garden balsam" always called henna. Despite they belong to two different kinds of flowers. People's mixed use of these two kinds of flower names reflects the profound impact of henna art on Chinese culture. Through the integration with Chinese life tradition and social aesthetics, the foreign custom of painting red nails was finally absorbed and evolved into a traditional Chinese festival folk activity. Not only that, but it also internalized as an important part of the women's cosmetic decoration and body aesthetics in traditional Chinese culture. All in all, this is a good example of material and cultural exchanges in Asia along the Silk Road.

\section{Acknowledgments}

This research has been financed by the major tender project of the National Social Science Foundation of China: "The Iconography of Art Exchanges between China and Foreign Countries along the Silk Road"(16ZDA173); China Scholarship Fund (201806630041).

\section{References}

Cartwright-Jones, C. (2009). The Techniques of Persian Henna (p. 9). Retrieved from http://www.hennapage.com/henna/encyclopedia/Persian_henna_Techniques.pdf

Editorial Board of Flora of China, Chinese Academy of Social Sciences. (2004). Flora of China (p. 111). Beijing: Science Press.

Ji, H. (263A.D./306A.D. 1726). The State of Vegetation in Southern China. Retrieved from http://www.guoxuemi.com/gjzx/607616zfqj/57728/

Li, H. (790A.D./816A.D. 2015). Li He's Poems (p. 66). Shanghai: Shanghai Ancient Books Publishing House.

Li, S. Z. (1518/1593. 1997, Vol. 2). Compendium of Materia Medica (pp. 1209-1210). Beijing: People's Medical Publishing House.

Lin, Q. S. (1973). The Chinese Herbal Composition Chemistry (p. 185). Beijing: People's Medical Publishing House.

Tan, Q. (1594/1658. 2006). ZaoLin Miscellany (Luo, Z.H, Trans., p. 462). Beijing: Zhonghua Book Company.

Wang, X. J. (1561/1653). The Anthography of Blossoms. Retrieved from http://www.guoxuemi.com/gjzx/807517frfg/69611/

Wu, W. L. (2019). Exotic herbs were introduced from the West: Henna's origin and development. Cultural Heritage Magazine, 111-116.

Xu, G. Q. (156/1633. 1979). The Agricultural Administration Book (Shi, S.H, Trans. p. 1406). Shanghai: Shanghai Ancient Books Publishing House.

Zhou, M. (1232/1298. 1997). Notes Written on Guixin Avenue (pp. 134-135). Beijing: People's Medical Publishing House.

Zhou, X., \& Gao, C. M. (1998). The Costume and Make-up of Chinese Women Through the Ages. Shanghai: Xuelin Press.

Zhu, S. (1361/1425. 2008). The Herbal for Relief of Famines (Ni, G. J, Trans. p. 79). Beijing: Agriculture and Science Press.

\section{Copyrights}

Copyright for this article is retained by the author(s), with first publication rights granted to the journal.

This is an open-access article distributed under the terms and conditions of the Creative Commons Attribution license (http://creativecommons.org/licenses/by/4.0/). 